\title{
Simulation Numerical Calculation of Mentality State Based on Network Visualization Design
}

\author{
Binghui Liang \\ Department of students' work, Guilin University of Electronic Technology, Guilin, 541004, China \\ liang_binghui22@163.com
} Keywords: Network environment; Character interaction; Psychological status; Character analysis;
MATLAB software; Simulation calculation

\begin{abstract}
In the network environment, the network interpersonal communication has become more and more frequent, and its accompanied by the personality interaction will affect the development of the students' psychological emotion, which has a great influence on the healthy growth of students. In network communication, psychological motivation is an important factor of leading to the role transformation, because the role transformation has certain regularity, and can have an impact on psychology and communication effect. In this paper, the character interaction theory is introduced into the analysis process of college students' network psychological, to establish a mathematical model of network character interaction, and then the calculation algorithm of MATLAB is compiled. Through the MATLAB simulation, we can get the quantitative curve analysis of network personality interaction factor, role positioning and status analysis, which provide a new computer method for the study of college students’ network psychology.
\end{abstract}

\section{Introduction}

As college students of the new age, a lot of people like online shopping and online dating etc.. Network is another virtual space free from the real world, and it provides a drama stage for the people, the people are free to choose the play, props and style. In the process of communication, the role is an important concept, but the network communication itself has the features of being virtual and duality, the playing in network communication is that the role theory is applied and alienation in network $[1,2]$. The network role will have a certain impact on the network mental state, the use of the VB software programming computation and visualization curves show and analyze the network psychology of college students, to get the relationship curve between the college students' network psychological character and network state, which is an innovative method of network psychology study.

\section{Overview of College Student's Network Character and Mental State Interaction}

Now college students' each person or each dormitory usually have a computer, it makes the college students contact with the network environment that is particularly high frequency, which is the main force of online interactive emotion information under the network environment [3]. With the extension of time, the network will have a relatively large change on the psychological influences factor of college students, especially in the effect of character interaction state, and the role will have a certain impact on the psychological state, the main link is shown in Figure 1.

Figure 1 shows the schematic diagram of college students' network psychological interactive process, it can be seen that network factors will change greatly under the influence of network environment, and the psychological character and psychological state of the different student group on the internet are statistical calculated by VB software, which can get the final analysis results of network psychology. 


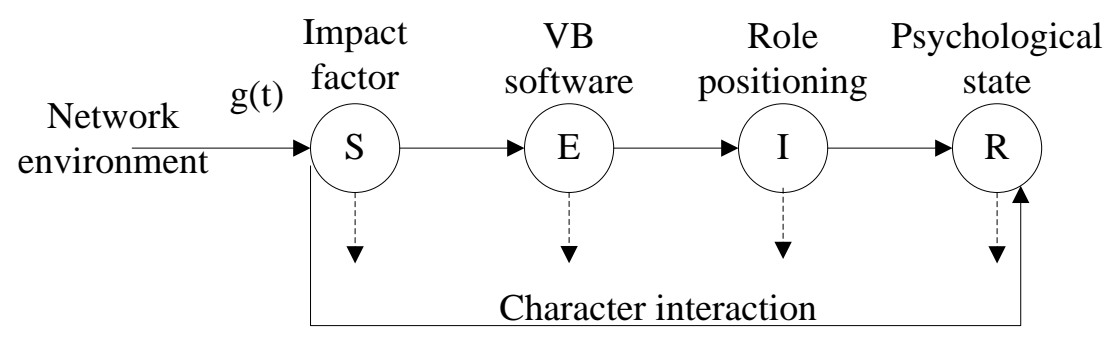

Fig.1: Schematic diagram of network psychological character interaction process

\section{Network Role Interactive Mathematics Model and Algorithm Design}

According to the character interaction of college students' network psychological, there are great uncertainty factors for each network students groups [4]. So, the mathematical model of network role and state should be calculated by the undetermined coefficient method, this paper uses the undetermined coefficient method to obtain the character interaction mental state function as shown in formula (1).

$$
\begin{aligned}
g(\xi, \eta)=d_{0} & +d_{1} \xi+d_{2} \eta+d_{3} \xi^{2}+d_{4} \xi \eta+d_{5} \eta^{2}+d_{6} \xi^{2} \eta+d_{7} \xi \eta^{2} \\
& +d_{8} \xi^{3}+d_{9} \eta^{3}+d_{10} \xi^{3} \eta+d_{11} \xi \eta^{3}
\end{aligned}
$$

Among them, $d$ shows undetermined parameters, $\xi$ and $\eta$ show undetermined function. Using the character interaction theory, assuming that the psychological role and psychological state are respectively denoted as $i$ and $j$, network mental performance function is denoted as $L$, we can get the function equation of role orientation and mental state as shown in formula (2).

$$
\left\{\begin{array}{l}
x=x_{i} L_{i}+x_{j} L_{j}+x_{k} L_{k} \\
y=y_{i} L_{i}+y_{j} L_{j}+y_{k} L_{k}
\end{array} .\right.
$$

This paper uses the influence factors, role orientation and mental state as the interpolation nodes, the use of the undetermined coefficient method can be obtained:

$$
g_{1}(x, y)=L_{1} u_{1}+L_{2} u_{2}+L_{3} u_{3} \text {. }
$$

Intermediate among the three parameters as interpolation nodes, hypothesis

$$
g_{2}(x, y)=c_{1} L_{1}^{2}+c_{2} L_{2}^{2}+c_{3} L_{3}^{2}+c_{4} L_{1} L_{2}+c_{5} L_{2} L_{3}+c_{6} L_{3} L_{1} .
$$

Using the undetermined coefficient method, it is obtained

$$
g_{2}(x, y)=\sum_{i=1}^{3} L_{i}\left(2 L_{i}-1\right) u_{i}+4\left(L_{2} L_{3} u_{4}+L_{1} L_{3} u_{5}+L_{1} L_{2} u_{6}\right)
$$

In order to realize the mathematical model and algorithm of college students' network psychology analysis and combined with neural network algorithm, this paper uses MATLAB software mathematical model to carry on calculation program, its used main program are as follows $[5,6]$ :

[dW,ls]=learngd(W,P,Z,N,A,T,E,gW,gA,D,LP,LS)

[db,ls]=learngd(b,ones(1,Q),Z,N,A,T,E,gW,gA,D,LP,LS)

info=learngd(code)

[net,tr,Y,E,Pf,Af]=train(NET,P,T,Pi,Ai)

[net,tr,Y,E,Pf,Af]=train(NET,P,T,Pi,Ai,VV,TV)

$\mathrm{k}=1$;

$\mathrm{p}=[-1: .05: 8]$

$\mathrm{t}=1+\sin \left(\mathrm{k}^{*} \mathrm{pi} / 4 * \mathrm{p}\right)$;

$\operatorname{plot}\left(\mathrm{p}, \mathrm{t}, \mathrm{\prime}^{-}\right)$;

title(' Psychological analysis function');

xlabel(' Time ');

ylabel(' Nonlinear function '); 


\section{Research on College Students Psychological Interaction Computing based on MATLAB Software}

In order to verify the validity and reliability of the mathematical model and the algorithm of network character interaction in second part, college students' psychological interaction has been calculated program by using MATLAB software [7]. And the individual psychological state and role has been made quantitative analysis by the visual function of using MATLAB software, the analysis of structure model is shown in Figure 2.

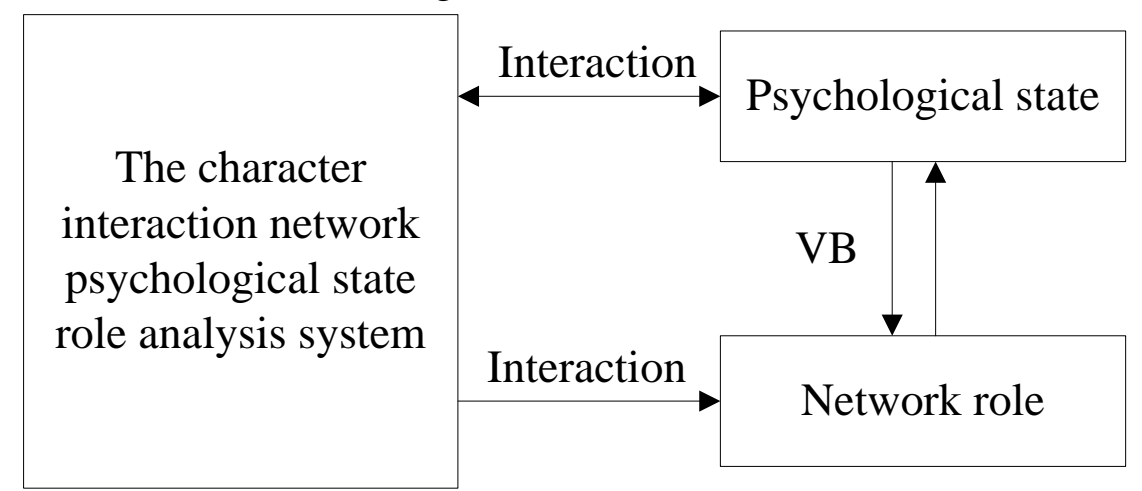

Fig.2: Interaction network analysis system

Figure 2 shows the schematic diagram of character interaction network analysis system, the psychological state and network role closely will be tied by using the interactive principle, and then the use of VB software makes a quantitative analysis on the psychological state and network role, the analysis system can carry out visual display, its operating window is shown in Figure 3.

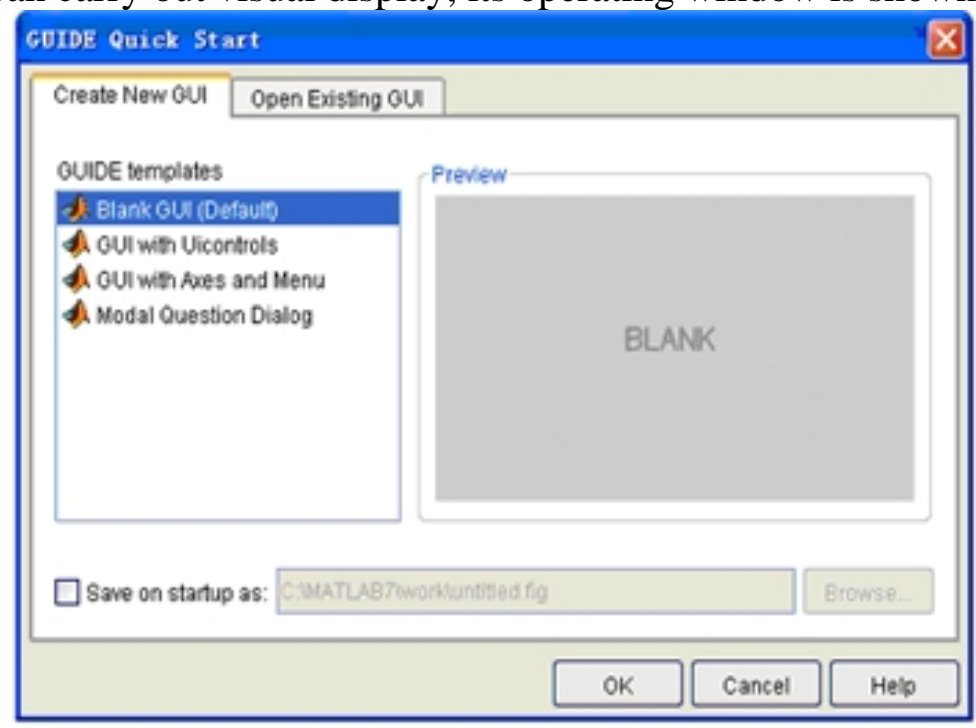

Fig.3: MATLAB GUI visualization interface

Figure 3 shows a schematic diagram of interface development using MATLAB GUI toolbox, it can be seen that we can build all kinds of buttons and visualization display window in the BLANK column, its calculated curve in this paper are directly displayed on the window, the display development interface is shown in Figure 4.

Figure 4 shows a visualization display window of college students' psychological character analysis, the main window is divided into two parts, one part is calculated link button, and another part is the visual display curve [8,9]. Through the mental state, psychological role and influence factor, this three buttons can get the network psychology and character analysis curve. 
Bile Edit Yier Insert Iools Resktop gindor Help

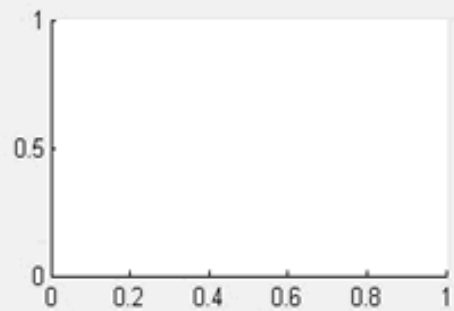

Mental

state

Menta
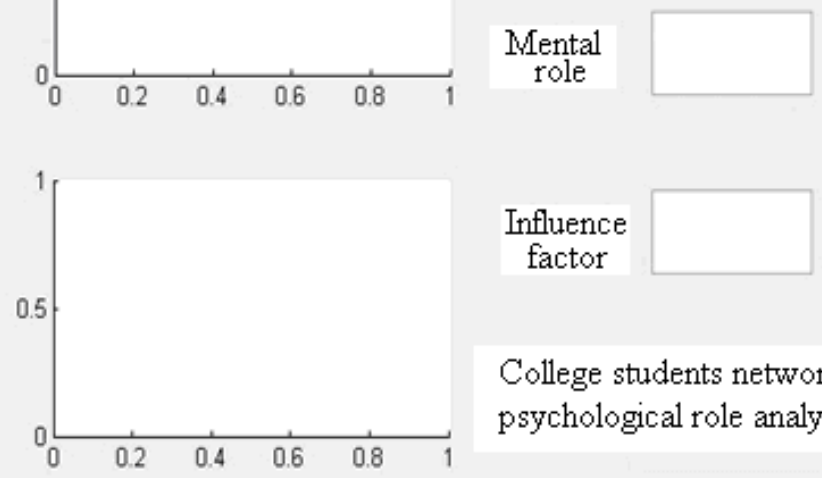

Influence

factor

College students network psychological role analysis

Fig.4: College students' psychological role analysis visualization window

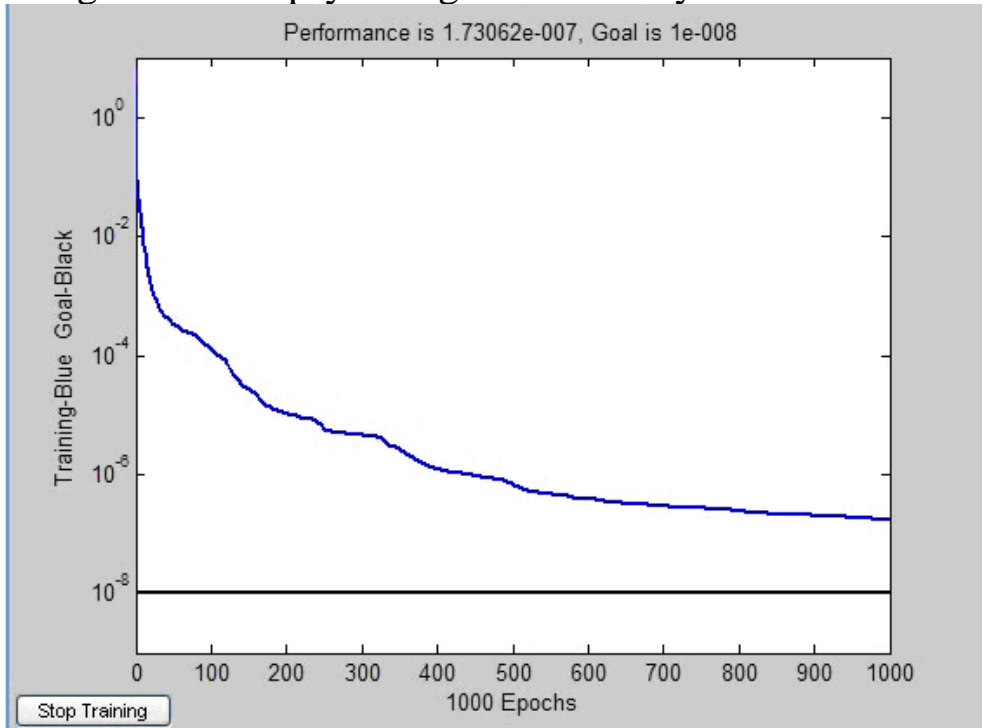

Fig.5: The calculation convergence residual curve

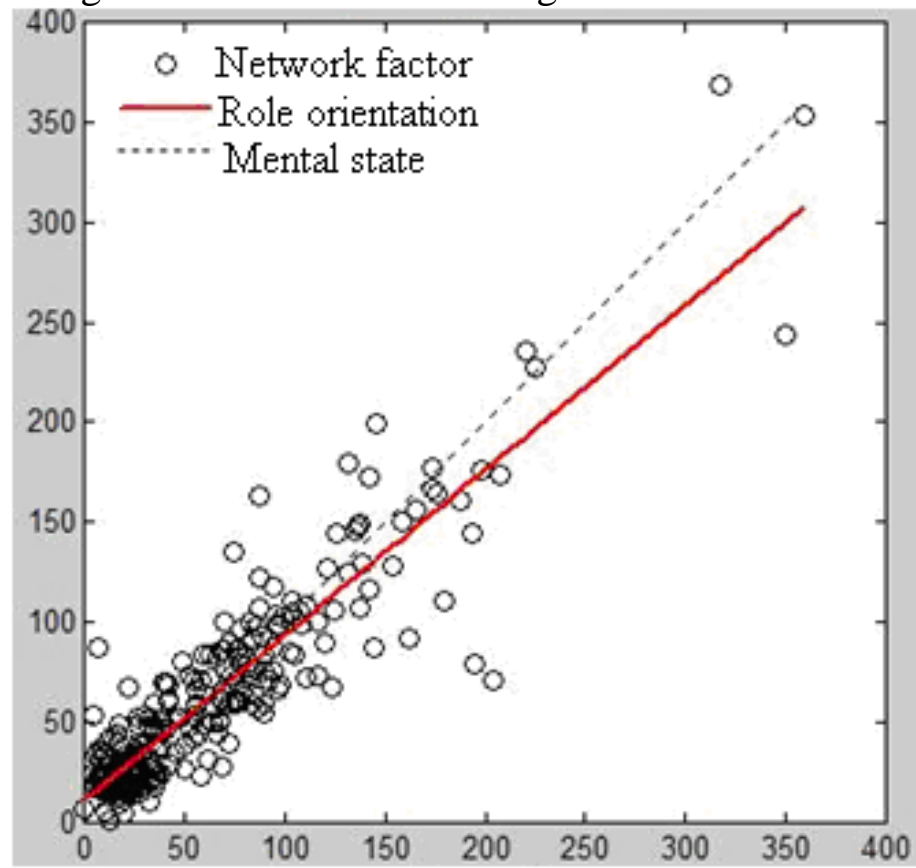

Fig.6: Network roles and status analysis curve 
Figure 5 shows the convergence curve that can be obtained by calculation with VB software, it can be seen from the chart that with the increase of the iteration number, the computation convergence error will be decreased, and when the iterative calculation is up to the 900 steps, the convergence error will be achieved below $10^{-4}$, it achieves high calculation accuracy.

As shown in Figure 6, it represents the VB analysis curve of network role and state, it can be seen from the chart that the different network produces the different network factors [10]. In the effects of network factor, the network psychological status and roles are different, because the role orientation will make the mental state showing a certain trend, and the network role and status can be statistical calculated by VB software, its results are shown in Table 1.

\begin{tabular}{llll}
\multicolumn{2}{l}{ Table 1. The network mental status and role analysis index table } \\
\hline $\begin{array}{l}\text { Actual } \\
\text { internet(days) }\end{array}$ & $\begin{array}{l}\text { Network } \\
\text { factor impact } \\
\text { index }\end{array}$ & $\begin{array}{l}\text { Role } \\
\text { positioning } \\
\text { impact index }\end{array}$ & $\begin{array}{l}\text { Psychological } \\
\text { state impact } \\
\text { index }\end{array}$ \\
\hline 50 & $30-60$ & 49.2 & 50.3 \\
100 & $80-110$ & 89.2 & 90.3 \\
150 & $120-150$ & 125.3 & 130.2 \\
200 & $160-190$ & 182.3 & 185.2 \\
250 & $200-230$ & 221.7 & 222.8 \\
\hline
\end{tabular}

Table 1 shows the obtained results table by using VB calculation. Through the computer statistics of different online population, the relationship index between psychological status and role has been obtained, the table can be seen that with the actual internet different days, networks factor are different on the influence index of role orientation and psychological state, in which the influence index of role orientation presents the standard index line, and psychological state is also gradually stabilized under the influence of role orientation [11,12]. Therefore, in order to make the college students network mental health, we need to consider psychological status and role with the influence of the network time, and the VB software can also be a computer method of psychological research.

\section{Summary}

(1) The paper establishes the mathematical model and calculation algorithm of collage students' learning network psychology analysis, and the character interaction theory is introduced into the model, and then using the undetermined coefficients design influence factor, role orientation and mental state model function.

(2) The visualization window of college students' network psychology analysis is designed by using GUI toolbox of MATLAB, at the same time the design of impact factor, role orientation and psychological state's computing the link button in the window can realize the visualization of network psychological analysis.

(3) Through the MATLAB simulation calculation, we obtain the quantitative analysis curve of network personality interaction factor, role orientation and status analysis, and according to the quantitative analysis curve, we can lead college students' network psychology to the healthy development, which provides the technical reference for the research of network psychology.

\section{Acknowledgments}

It was supported by General Research Projects in Colleges and Universities in Guangxi in 2014 with the granted number [2014]8. And the project's name is Research and Practice of gratitude education and sense of Guangxi College Students From the perspective of Chinese dream with the project No. LX2014151 and the project is hosted by Liao Kemin. 


\section{References}

[1] Xie Yujin, Hu Shuxiang. Study on the new focus of network user contradictions and network ideological and political education [J]. Study of ideological and theoretical education 2012(6): 67-69.

[2] Yuan Lin, Li Meiqing. The difficulties and countermeasures research on ideological and political education network communication process management [J]. Journal of ideological and theoretical education, 2011(3): 45-47.

[3] Jiang Xiaoli. Study of college students' network ideological and political education effectiveness evaluation system [J]. Education research, 2011(1): 23-24.

[4] Deng Zhuoming. Basic experience of leading the social trends thought in collage [J]. Collage theory front, 2012(11): 34-36.

[5] Liu Jianjun. The subject construction of ideological and political education [J]. Ideological and political education, 2011, 21(3): 38-45.

[6] Zheng Yongting. The subject of ideological and political education research emphasis and difficulties [J]. Ideological education research, 2013(5): 3-7.

[7] Xiang Qingping. Review and suggestions: the domestic network political participation and research in recent years [J]. Journal of Party School of CPC Hangzhou Municipal Committee, 2011(4): 57-58.

[8] Zhang Zaixing. Study of network ideological and political education [M]. Beijing: Economic Science Press, 2012: 67-80.

[9] Zhao Xiang, Li Zhishu. The implementation of JUnit test case automatic generation based on invariant detection [J]. Computer application, 2007, 27(6): 319-321.

[10] Ceng Changqiu, Wan Xuefei. Teenagers surf internet and network civilization construction [M]. Changsha: Hunan people's publishing house, 2012: 89-110.

[11] Liu Xingeng. Modern ideological and political education methods theory [M]. Beijing: People's publishing house, 2012: 112-130.

[12] Li Heliang. Analysis and construction: the contemporary China ideological and political education philosophical reflection [M]. Beijing: People's publishing house, 2011: 312-320. 